\title{
Determination of Hydraulic Conductivity of Undisturbed Soil Column: a Measurement Accomplished with the Gamma Ray Transmission Technique
}

\author{
Anderson Camargo Moreira ${ }^{*}$, Otávio Portezan Filho², \\ Fábio Henrique de Moraes Cavalcante ${ }^{3}$ and Carlos Roberto Appoloni ${ }^{2}$ \\ 1 Programa de Pós Graduação em Ciências e Engenharia de Materiais/EMC, \\ Universidade Federal de Santa Catarina - UFSC, \\ ${ }^{2}$ Depto. de Física, Universidade Estadual de Londrina - UEL, \\ ${ }^{3}$ Centro de Física Nuclear, Instituto Superior de Engenharia/DEEA/ISEL, \\ Universidade de Lisboa, \\ 1,2Brasil \\ ${ }^{3}$ Portugal
}

\section{Introduction}

The determination of hydraulic conductivity is an important parameter on the description of water transportation in complex porous systems, such as soil. Darcy Buckingham equation describes the water movement in unsaturated porous media. This parameter is given in terms of moisture content expressed by their moisture content or its potential energy. The soil hydraulic conductivity is a property of each pore system since it depends on the shape and geometrical arrangement of its particles. The study of hydraulic conductivity for unsaturated soils can be used to analysis the irrigation, drainage and nutrient transport, also for development of an agricultural crop. The description of the water flow in soil is important for design irrigation projects, erosion control and even control of movement of toxic waste from the surface to deeper horizons.

The first experimental study on the movement of water in the soil was done by Henry Darcy in 1856, using soil columns of saturated sand (Darcy, 1856). In 1907, Edgar Buckinghan described the water flow in unsaturated porous media modifying the equation obtained by Darcy (Buckingham, 1907). In 1931, Lorenzo Adolph Richards combined the equations of Darcy and Buckingham with the equation of continuity to establish an overall relationship, which is yet used (Richards, 1931). Klute describes several methods for estimating the hydraulic conductivity and diffusivity for unsaturated soils in natura and in laboratory (Klute, 1972), including the Instantaneous Profile Method, (Sisson et al., 1980).

The Gamma Ray Transmission (GRT) technique in physics of soil was first applied to density measurements, according to Reginato \& Van Bavel, 1964, and later for determination of soil moisture content. One of the earliest work using the GRT technique was carried out by Reichardt, 1965 . The GRT allows nondestructive measurements of density and soil 
moisture content, study of soil compaction caused by agricultural machinery and also the monitoring of changes in soil profile density (Portezan Filho, 1997).

In order to do descriptive measurements of hydraulic conductivity of soil, crop growing conditions should be complied with in situ analysis (Chong et al., 1981, Libardi et al., 1980, Hillel et al., 1972). However, laboratory analysis can recreate the environment field simulating rainfall or irrigation procedures with controlled water infiltration in undisturbed soil columns. The undisturbed columns preserve the soil structure in natura and can be moved to laboratory for analysis. Studies of disturbed soil columns for some purposes are found in literature (Ying et al., 2010, Al-Houri et al., 2009), however, analysis of undisturbed soil columns are relatively novel concept (Coppola et al., 2004).

This chapter introduces a non conventional technique for determining the hydraulic conductivity in soils [K $(\theta)$ ], the of Gamma Rays Transmission method, which together with the methods of Sisson et al., 1980 was adopted to analyze the conductivity of undisturbed soil columns.

\section{Methodology}

\subsection{Gamma RaysTransmission}

Each one of these processes produces a complete or partial transfer of energy from a photon to an electron of the sample, contributing to definition of the mass attenuation coefficient $[\mu$ $\left.\left(\mathrm{cm}^{2} \cdot \mathrm{g}^{-1}\right)\right]$ of the material. The $\mu$ coefficient will define the rate of radiative absorption by matter. It is an intrinsic property of each material with density $\left[\rho\left(\mathrm{g} . \mathrm{cm}^{-3}\right)\right]$ and atomic number $(Z)$ defined. In the case of materials with several density and chemical composition, the volume fraction crossed by the radiation beam has a particular mass attenuation coefficient. The exponential absorption which characterizes the passage of a monoenergetic electromagnetic radiation through a homogeneous material is given by the Beer-Lambert Law (Siegbahn, 1965) given by:

$$
I=I_{0} e^{-\mu \rho x}
$$

A photon detector converts photons into electrical pulses. These pulses are measurable by the detection system, each counted pulse is called "count". The intensity of the radiation from a source " $I_{0}$ " is the ratio between the number of counts and the exposure time (s). The intensity " $I$ " of the beam that was attenuated in by the object with a thickness $x(\mathrm{~cm})$ is quantified in the same way, ie:

$$
I=\frac{N}{t}
$$

were $N$ is the total number of counts.

The radiation beam in the technique GRT has a thickness defined by the use of collimators, assuming a cylindrical shape with a diameter defined. Thus, the determination of the mass attenuation coefficient can be done point to point in the sample, allowing analyzing a density profile of the material.

\subsection{Sisson method}

Working in laboratory with saturated porous material, Darcy found a proportional relationship between density of water flow and hydraulic gradient. 
The constant of proportionality was called "saturated hydraulic conductivity". With the experimental results for the water flow in unsaturated soils columns, Buckingham obtained a similar equation. Richards called it the Darcy-Buckingham equation. For the water flow in a soil sample with rigid structure, the flow can be written as:

$$
\vec{q}=-K(\theta) \operatorname{grad} H
$$

where the $\vec{q}$ vector is the density of water flow in soil (m.s $\left.\mathrm{s}^{-1}\right)$, grad $H$ is the vector gradient of hydraulic potential $\left(\mathrm{cm} . \mathrm{cm}^{-1}\right)$ and $\mathrm{K}(\theta)$ is the hydraulic conductivity of the sample $\left(\mathrm{m} . \mathrm{s}^{-1}\right)$ of soil, function of soil moisture content with rigid porous media. The Sisson method assumes that the one-dimensional water flow in porous media, in z-direction from the surface of soil to down, can be described by Richards equation:

$$
\frac{\partial \theta(z, t)}{\partial t}=\frac{\partial}{\partial z}\left\{K(\theta) \frac{\partial H(z, t)}{\partial z}\right\}
$$

and the hydraulic potential gradient is unitary:

$$
\frac{\partial H(z, t)}{\partial z}=\frac{\partial(h+z)}{\partial z}=-1
$$

During the process of water redistribution in the saturated soil, Sisson considers the hydraulic conductivity $\mathrm{K}(\theta)$ an exponential function of soil moisture $\theta$, according to the equation below:

$$
K(\theta)=K_{s} e^{\left[\gamma\left(\theta-\theta_{s}\right)\right]}
$$

where $\mathrm{K}_{\mathrm{S}}$ and $\theta_{S}$ are the values of saturated hydraulic conductivity and moisture respectively. The equation (6) can be described as follows:

$$
\frac{\partial \theta}{\partial t}=-\frac{\partial K(\theta)}{\partial z}=-\frac{d K(\theta)}{d \theta}\left(\frac{\partial \theta}{\partial z}\right)
$$

According to Jones \& Wagenet, 1984, for the solution of this equation Sisson, used the techniques of resolution of ordinary differential equations presented by Lax, 1972. The algorithm of Lax allows the solution of equation (7). The solution for $z=L$, is given by:

$$
\theta_{s}-\theta=\left(\frac{1}{\gamma}\right) \ln t+\left(\frac{1}{\gamma}\right) \ln \left(\frac{\gamma K_{s}}{L}\right)
$$

where $\theta_{S}$ is the moisture content saturation calculated by experimental data moisture $\theta$ of the water redistribution for every depth level $\mathrm{z}=\mathrm{L}$, through the model $\theta$ versus $\ln$ t for a short time (0.0007 day, practically zero). By some algebraic manipulations of the equation (8), it is obtained:

$$
\ln \left(\frac{L}{t}\right)=\ln \left(\gamma K_{s}\right)+\gamma\left(\theta-\theta_{s}\right)
$$


This is the equation presented by Sisson et al., 1980. Performing a linear regression lnt versus $\left(\theta-\theta_{S}\right)$ for each depth level $\mathrm{L}$, the values of the constants $\mathrm{K}_{S}$ (saturated hydraulic conductivity) and $\gamma$ can be determined.

\section{Materials and methods}

\subsection{Nuclear apparatus}

The equipment adopted at this work was a 2"x2" diameter NaI (Tl) scintillation detector, 2 $\mathrm{mm}$ diameter source and $5 \mathrm{~mm}$ diameter detector lead collimators, standard gamma spectrometry electronic constituted by pre-amplifier, amplifier and high voltage supply (HV). The radiation source was an Americium-241 (241 Am) source with $59.6 \mathrm{keV}$ energy and $100 \mathrm{mCi}$ activity. The nuclear setup is coupled to a sample holder system that movement vertically the soil column. Figure 1 shows the gamma ray transmission experimental set-up.

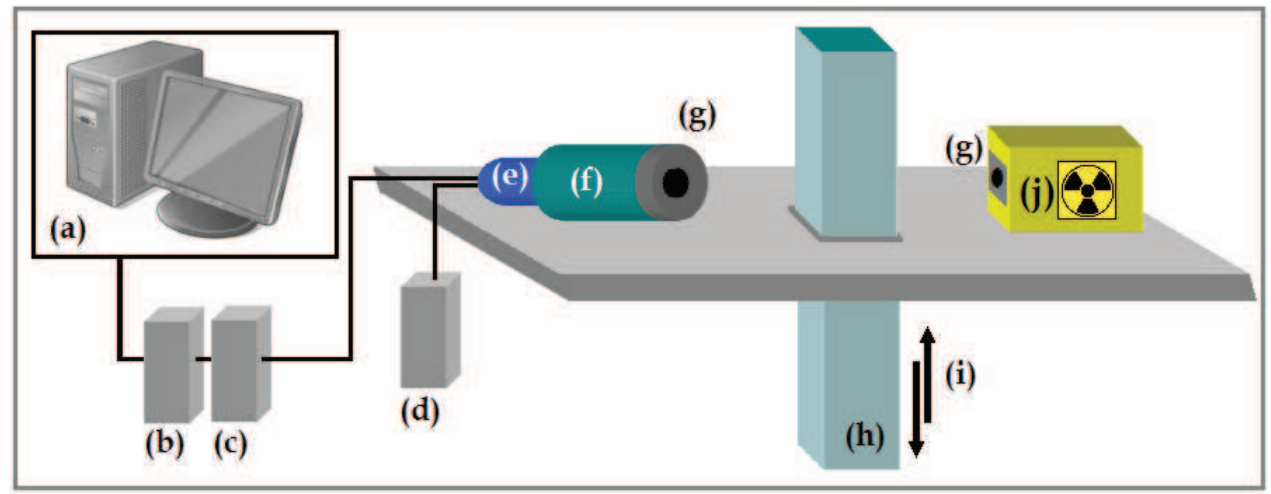

Fig. 1. Nuclear setup constituted by (a) data acquisition station, (b) signal amplifier and (c) pre-amplifier, (d) high voltage supplier, (e) photomultiplier, (f) NaI detector, (g) $\mathrm{Pb}$ collimators, (h) soil column, (i) sample holder with vertically movement and (j) ${ }^{241} \mathrm{Am}$ gamma ray source.

\subsection{Soil column}

Undisturbed soil columns were taken from the campus of the State University of LondrinaUEL, Brazil, in a region destined to agronomic studies. The soil of the place is categorized as dystrophic dark red latossol. For the soil columns extract, some equipment are required like shovels, hoes and garden trowels, gauzes and paraffin as well stove and metal container for melting the paraffin. In a trench with about $60 \mathrm{~cm}$ deep, the column was molded into one wall of the trench with the garden trowels. With $40 \mathrm{~cm}, 10 \mathrm{~cm}$ wide and $5 \mathrm{~cm}$ thick, the column was wrapped with a layer of gases that absorbed the previously melted paraffin. When dry, the layer of gas and paraffin formed a shield that contained the undisturbed soil for its transport to the laboratory LFNA, Applied Nuclear Physics Laboratory, located in the Physics Department/UEL.

Six columns of undisturbed soil were extracted from the trench, but only one column resisted the transporting to the laboratory or no presented cracks in the interface between shield and soil. About $5 \mathrm{~kg}$ of soil samples were also collected from the trench for determination of initial moisture content of the soil. 


\subsection{Soil column gammagraphy}

To use the Sisson model the gammagraphy of the column should be accomplished. Gammagraphy is a scan of the column with the gamma beam used for the estimation of any parameters of the equation 9. As shown in Figure 2, the scanning is performed at the measuring points pre-determined over the soil column.

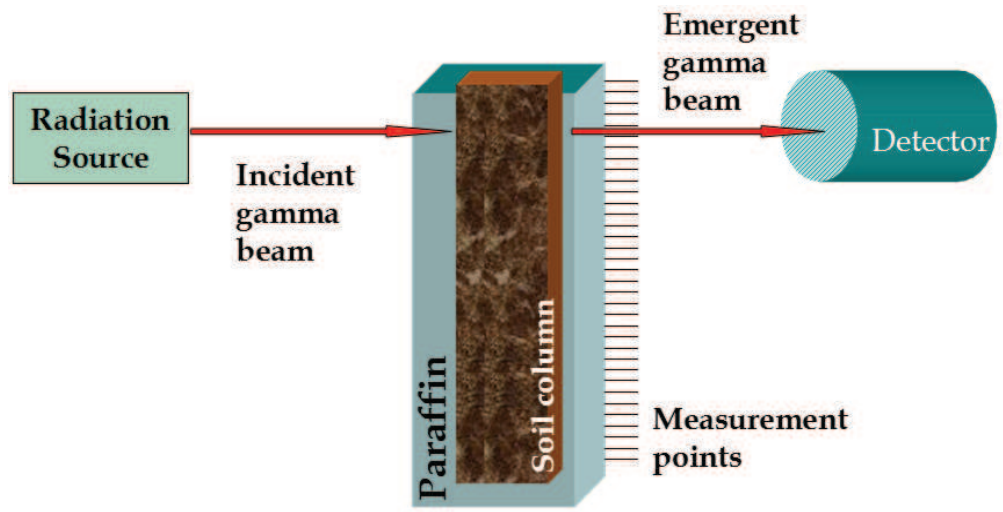

Fig. 2. Process of gammagraphy of the soil column.

The gammagraphy should be performed in the column with soil and in the empty column, ie, only in the paraffin that surrounds the soil. For the column with soil, Figure 3 shows the thickness crossed by the gamma beam. The air and paraffin shield attenuation are inserted in the initial beam intensity $I_{0}$.

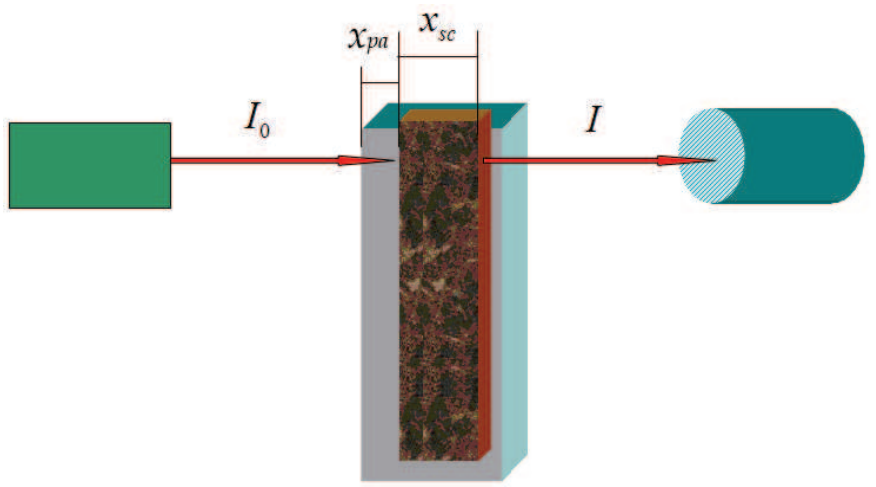

Fig. 3. Gammagraphy setup of column with soil.

The undisturbed soil column is constituted by soil, initial moisture content and porosity, so the $x_{s c}$ thickens is given by:

$$
x_{s c}=x_{s}+x_{w}+x_{p a}
$$

where $x_{s c}$ is the thickness of the soil column, $x_{s}$ is the equivalent thickness of the soil, $x_{w}$ is the equivalent thickness of the water and $x_{p}$ is the equivalent thickness of the pores. Considering the equation 10, equation 1 can be written as follows: 


$$
I=I_{0} \exp -\left(\mu_{s} \rho_{s} x_{s}+\mu_{w} \rho_{w} x_{w}+\mu_{p} \rho_{p} x_{p a}\right)
$$

Denoting by $\theta_{s}, \theta_{w}$ and $\theta_{p}$, the volumetric fraction of soil, water and the pore within the sample, respectively, is given that:

$$
\theta_{s}+\theta_{w}+\theta_{a}=1
$$

Considering the space of the soil, water and pore in terms of "volume", $V_{s}=V \theta_{s}, V_{w}=V \theta_{w}$, $V_{p}=V \theta_{p}$, where $V$ is the total sample volume, and also the equivalent thickness as $x_{s}=x \theta_{s}$, $x_{w}=x \theta_{0}, x_{a}=x \theta_{a}\left(\theta_{0}\right.$ is the initial moisture content), equation 11 can be written as:

$$
I=I_{0} \exp -\left(\mu_{s} \rho_{s} x \theta_{s}+\mu_{w} \rho_{w} x \theta_{0}+\mu_{p} \rho_{p} x \theta_{p}\right)
$$

According to Portezan Filho, $1997 \mu_{p} \rho_{p} x \theta_{p}$ is very small in relation to the other terms of the exponential and can be unvalued. Thus, equation 13 becomes:

$$
I=I_{0} \exp -\left(\mu_{s} \rho_{s} x \theta_{s}+\mu_{w} \rho_{w} x \theta_{0}\right)
$$

The soil bulk density $\rho$ is denoted by $\rho=\rho_{s} \theta_{s}$, and considering the water density as $\rho_{w}=1$ g.cm-3 , equation 14 becomes:

$$
I=I_{0} \exp -\left(\mu_{s} x \rho+\mu_{w} x \theta_{0}\right)
$$

For the gammagraphy of the paraffin shield, first it is considered the column with dry soil. As can be seen in the Figure 3, $x_{p a}$ is the paraffin thickness, $I_{0}$ and $I$ (intensity of the gamma beam emergent from the soil column without paraffin shield) become $I_{0 s}$ (average of the measurement points) and $I_{s}$ (intensity of the gamma beam emergent from the soil column with paraffin shield), respectively, thus the following equation can be written as:

$$
I=\overline{I_{0 s}} \exp -\left(x_{p a} \mu_{p} \rho_{p}+x \mu_{s} \rho+x \mu_{w} \theta_{0}\right)
$$

Considering the empty column, ie, only the paraffin that shields the soil, as shown in Figure 4 , the equation 16 can be written as:

$$
I=\overline{I_{0 p a}} \exp -\left(x_{p a} \mu_{p} \rho_{p}\right)
$$

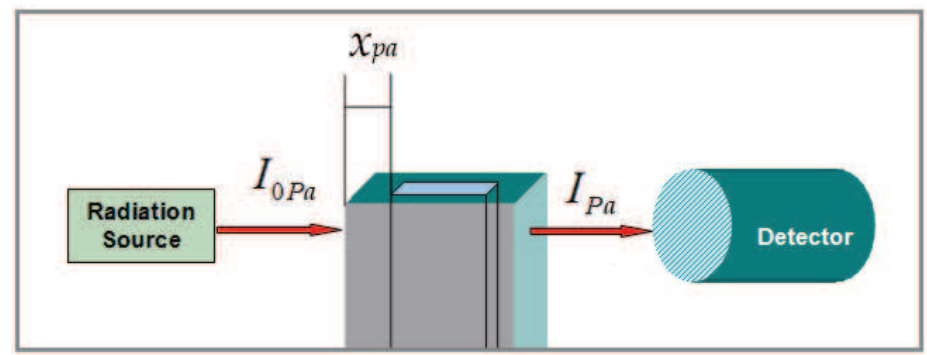

Fig. 4. Gammagraphy of the paraffin that shields the empty the soil column. 
Dividing the equation 16 by 17 , and with some algebraic manipulations, the result is given by:

$$
\mu_{s} \rho=\frac{1}{x_{s c}} \ln \left(\frac{I_{p a}}{I_{s}} \frac{\overline{I_{0 s}}}{\overline{I_{0 p a}}}\right)-\mu_{w} \theta_{0}
$$

where $I_{0 s}$ and $I_{0 p a}$ are the average intensity of the gamma beam incident on the soil column and empty column (cont.s-1), respectively, $I_{s}$ and $I_{p a}$ are the average intensity of the gamma beam incident on the soil column and empty column (cont.s $\left.{ }^{-1}\right), x_{s c}$ is the thickness of the soil column $(\mathrm{cm}), \theta_{0}$ is the initial moisture content $\left(\mathrm{cm}^{3} \cdot \mathrm{cm}^{-3}\right)$ and $\mu_{w}$ is the water mass attenuation coefficient $\left(\mathrm{cm}^{2} \cdot \mathrm{g}^{-1}\right)$. This equation allows the determination of mass attenuation coefficient of the soil $\mu_{s}$. If soil density $\rho\left(\mathrm{g} . \mathrm{cm}^{-3}\right)$ is not known, this parameter should be determined by the gravimetric method presented in the preceding item.

For the measurements of moisture content profiles $\theta(z, t)$ in function of the time and depth level, after water infiltration in soil column, equation 16 can be described as:

$$
I=\overline{I_{0 s}} \exp -\left(x_{p a} \mu_{p} \rho_{p}+x \mu_{s} \rho+x \mu_{w} \theta\right)
$$

where $\mathrm{I}$ is the intensity of the gamma beam emergent from the soil with water (cont.s ${ }^{-1}$ ) and $\theta$ is the moisture content $\left(\mathrm{cm}^{3} \cdot \mathrm{cm}^{-3}\right)$.

Inserting the equation 16 in the equation 19, the new equation is given by:

$$
I=I_{s} \exp \left(x_{p a} \mu_{p} \rho_{p}+x \mu_{s} \rho+x \mu_{w} \theta_{0}\right) \exp -\left(x_{p a} \mu_{p} \rho_{p}+x \mu_{s} \rho+x \mu_{w} \theta\right)
$$

With some algebraic manipulations, equation 20 becomes:

$$
I=I_{s} \exp -\left\{x \mu_{w}\left(\theta-\theta_{0}\right)\right\}
$$

Inserting the exponential term of the equation 17 in the equation 16 , the result is given by:

$$
I_{s}=\frac{\overline{I_{0 s}} I_{p a}}{\overline{I_{0 p a}}} \exp -\left\{x\left(\mu_{s} \rho_{s}-\mu_{w} \theta_{0}\right)\right\}
$$

Inserting the $I_{S}$ from the equation 22 in the equation 21 :

$$
I=\frac{\overline{I_{0 s}} I_{p a}}{\overline{I_{0 p a}}} \exp -\left\{x\left(\mu_{s} \rho_{s}-\mu_{w} \theta_{0}\right)\right\} \exp -\left\{x\left(\mu_{w} \theta-\mu_{w} \theta_{0}\right)\right\}
$$

With some algebraic manipulations, equation 23 becomes:

$$
\frac{\overline{I_{0 p a}} I}{\overline{I_{0 s}} I p a}=\exp -\left\{x\left(\mu_{s} \rho_{s}+\mu_{w} \theta\right)\right\}
$$

Applying the neperian logarithm $(\ln )$ on each side of the equation 23 and inserting the exponential term on the equation 24 , and isolating $\theta(z, t)$, the result is:

$$
\theta(z, t)=\frac{1}{x \mu_{w}}\left[\ln \left(\frac{I_{p a} \overline{I_{0 s}}}{I_{s} \overline{I_{0 p a}}}\right)-x \mu_{s} \rho_{s}\right]
$$


where $\mu_{w}$ is the water mass attenuation coefficient $\left(\mathrm{cm}^{2} \cdot \mathrm{g}^{-1}\right), x$ is the thickness of the soil column $(\mathrm{cm}), I_{P}$ and $I_{S}$ are the intensity of the gamma beam emergent from the empty column and soil column (cont.s ${ }^{-1}$ ), respectively, $I_{O P}$ and $I_{O S}$ are the average intensity of the gamma beam incident on the empty column and soil column (cont. $\mathrm{s}^{-1}$ ), respectively. With the processes of infiltration and redistribution of the water in soil, the values of moisture content $\theta(z, t)$ at each depth level of the soil column were calculated using the equation 25. With the data of moisture content variation at each depth level, the hydraulic conductivity $\mathrm{K}(\theta)$ was determined applying the model of Sisson.

\subsection{Soil density and humidity}

In order to determine the $\theta_{0}$ and $\rho_{s}$ parameters, the gravimetric method was adopted. For these determinations beakers, electric kiln and digital balance are required. The soil sample that was collected from the trench was sieved and packed in the beakers with know volume. The mass of the beaker with soil was measured after and before the drying process in the kiln $\left(24\right.$ hours at $105^{\circ} \mathrm{C}$ ). The difference in mass before and after drying is the mass of moisture content of the sample from the trench, which is also considered as being the moisture content present in the soil column.

To measure the initial moisture content of soil sample $\left(\theta_{0}\right)$, we have the following equation:

$$
\theta_{0}=\frac{m_{\mathrm{H}_{2} \mathrm{O}}}{V_{B}}
$$

where, water density is $1\left(\mathrm{~g} \cdot \mathrm{cm}^{-3}\right), \theta_{0}$ is the initial moisture content $\left(\mathrm{cm}^{3} \cdot \mathrm{cm}^{-3}\right), m_{\mathrm{H} 2 \mathrm{O}}$ is the water mass $(\mathrm{g})$ and $V_{B}$ is the water volume $\left(\mathrm{cm}^{3}\right)$.

Soil density $\left[\rho_{\mathrm{s}}\left(\mathrm{g} \cdot \mathrm{cm}^{-3}\right)\right]$ was determinate with the following equation:

$$
\rho_{s}=\frac{m_{S}}{V_{A C}}
$$

where $m_{S}$ is the soil mass $(\mathrm{g})$ and $V_{A C}$ is the sample holder volume.

\subsection{Mass attenuation coefficients}

The determination of the water mass attenuation coefficient $\left[\mu\left(\mathrm{cm}^{2} \cdot \mathrm{g}^{-1}\right)\right]$ has dual importance in the process of analysis of soil hydraulic conductivity, besides being an important factor present in the equations that predict the conductivity, is also used as a parameter in checking the effectiveness of the transmission system, including collimation, stability of electronic and deviations inherent of the equipment.

In this procedure a rectangular acrylic box is used as a sample holder. The box is irradiated empty at several measurement points, as can be seen in the Figure 5. The transmission is performed in the empty box to measure $I_{0}$ of the equation 1 . The $I_{0}$ is given as the intensity of the gamma beam radiation emergent from the sample holder, instead the intensity of the beam incident on the sample. 


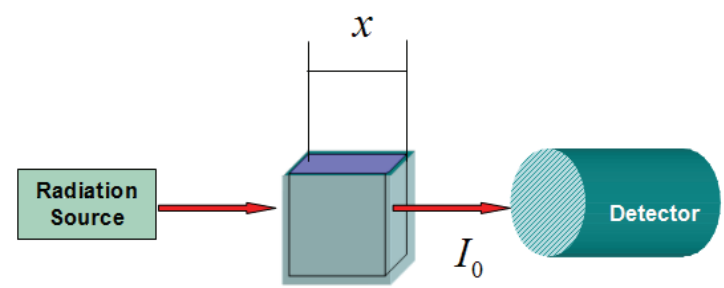

Fig. 5. Sample holder setup for $\mu_{w}$ and $\mu_{s}$ determinations.

After that, the box is filled with water and the transmission is performed again, where the equation 1 takes the following form:

$$
I=I_{0} e^{-\mu_{w} x}
$$

The same procedure is accomplished with the sample holder filled with soil:

$$
I=I_{0} e^{-\mu_{s} \rho_{s} x}
$$

where $\rho_{s}$ is given by the equation 27 and $x$ is the internal width of the sample holder.

\section{Preliminary measurements}

\subsection{Soil density and mass attenuation coefficients}

Following the script of section 3.4, the soil density $\left(\rho_{s}\right)$ of the trench and its initial moisture content $\left(\theta_{0}\right)$ was determined. The values are $\rho_{s}=1.48 \mathrm{~g} . \mathrm{cm}^{-3}$ and $\theta_{0}=0.223 \mathrm{~cm}^{3} . \mathrm{cm}^{-3}$.

To determine the mass attenuation coefficients of water and soil, was used the equations 28 and 29. Was used the exposure time $t=300 \mathrm{~s}$ for both. Six measures points were adopted in the acrylic box for the three situations, empty box, box filled with water and soil. The determined values, an average of six measures, were $\mu_{s}=0.4114 \pm 0.0045 \mathrm{~cm}^{2} \cdot \mathrm{g}^{-1}$ and $\mu_{w}=$ $0.02016 \pm 0.00002 \mathrm{~cm}^{2} \cdot \mathrm{g}^{-1}$.

Table 1 presents values of mass attenuation coefficients of water found in literature, for the same gamma energy used in this work, and also the value determined with the WinXCOM program. This software determines the mass attenuation coefficients for materials by their chemical composition and energy of the radioactive source (Gerward et al., 2001, Moreira et al., 2006).

\begin{tabular}{|l|c|}
\hline \multicolumn{1}{|c|}{ authors } & $\mu_{w}\left(\mathrm{~cm}^{2} \cdot \mathrm{g}^{-1}\right)$ \\
\hline Current work & $0.02016 \pm 0.00002$ \\
\hline Oliveira, 1991 & $0.0200 \pm 0.0002$ \\
\hline Ferraz, 1974 & $0.0200 \pm 0.0002$ \\
\hline Appoloni \& Rios, 1994 & $0.0267 \pm 0.0001$ \\
\hline WinXCOM (Gerward et al., 2001) & 0.0207 \\
\hline
\end{tabular}

Table 1. Values of the water mass attenuation coefficient.

The good agreement among the $\mu_{w}$ values shown in Table 1 indicates that the gamma ray transmission system is able to accomplish the measurements. 


\subsection{Undeformed soil column gammagraphy}

With the soil column placed on the measurement table (Figure 1), the process of gammagraphy of soil column has begun and the column is still dry. The column was measured at 12 points (space between two points of $2 \mathrm{~cm}$ ), starting at $\mathrm{z}=2 \mathrm{~cm}$ to $\mathrm{z}=24 \mathrm{~cm}$ depth levels and exposure time was $60 \mathrm{~s}$ per point. This procedure is also known as densitometry, because analyze the homogeneity of the density profile within the soil column in relation to the depth. The presence of voids that have great influence on the process of hydraulic conductivity can be detected.

The densitometry process is described in section 3.3. and the equation used was the 18 . The gammagraphy of the paraffin shield of the column was performed after the process of infiltration and redistribution of water in soil. At this stage, the column needs to be open and have the soil removed.

Figure 6 presents the graphic $\rho\left(\mathrm{g} \cdot \mathrm{cm}^{-3}\right)$ versus $\mathrm{z}(\mathrm{cm})$. The density homogeneity along the column can be noted. The lowest value of density was $\rho=1.347 \pm 0.039 \mathrm{~g} . \mathrm{cm}^{-3}$ at depth level $\mathrm{z}=10 \mathrm{~cm}$ and the highest was $\rho=1.654 \pm 0.048 \mathrm{~g} \cdot \mathrm{cm}^{-3}$ at depth level $\mathrm{z}=4 \mathrm{~cm}$.

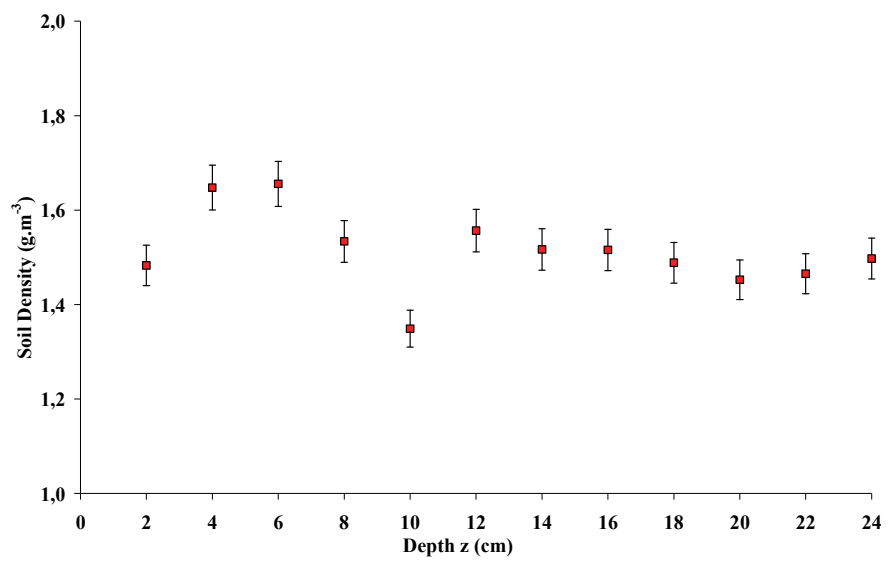

Fig. 6. Soil column densitometry.

\subsection{Infiltration and redistribution of water in soil column}

With the densitometry performed, the soil column was prepared for the infiltration of water into undisturbed soil. The top of the column was cut and a thin layer of soil was removed. Five layers of filter paper and a polymeric foam were placed on the surface of soil. This way, the direct contact between soil and water was avoided and a homogeneous infiltration with a low water flow was performed. Water was infiltrated keeping a water layer of approximately $0.5 \mathrm{~cm}$ on the top of the column. The gamma beam was kept in depth level $\mathrm{z}$ $=32 \mathrm{~cm}$ and the gamma beam intensity was constantly measured with $t=60 \mathrm{~s}$. The infiltration was completed when the gamma beam intensity was changed. This change indicated the water reached the point $\mathrm{z}=32 \mathrm{~cm}$. When the infiltration finished, the soil column was sealed to avoid water evaporation and the redistribution measurements started. The redistribution measurements analyze the movement of water in the soil column and determine the function of hydraulic conductivity $K(\theta)$ with the methodology adopted. The distance between measurement points was $2 \mathrm{~cm}$, from the depth $\mathrm{z}=2 \mathrm{~cm}$ to $\mathrm{z}=20 \mathrm{~cm}$. The 
determination of moisture content at each point was done with the equation 25 . Several data were needed to follow the variation of moisture content in the depth levels. The redistribution process was accomplished in 22 days. In the beginning, 9 measurements were made with interval of $20 \mathrm{~min}$, and subsequently increased to $40 \mathrm{~min}$.

Figures $7,8,9,10$ and 11 presents the graphics of moisture content $\theta(z, t)$ at each point versus time for the depth levels $\mathrm{z}=8,12,16,18$ and $20 \mathrm{~cm}$, respectively, the curve fitting coefficient (regression $\mathbf{r}$ ) to the experimental data are also presented. Analyzing the graphs, we notice a decrease in moisture content with the increase of the time, characteristic of the process of draining water. Theres a accentuated decrease of moisture content in the first two days of redistribution and the results from the four day no present significant changes.

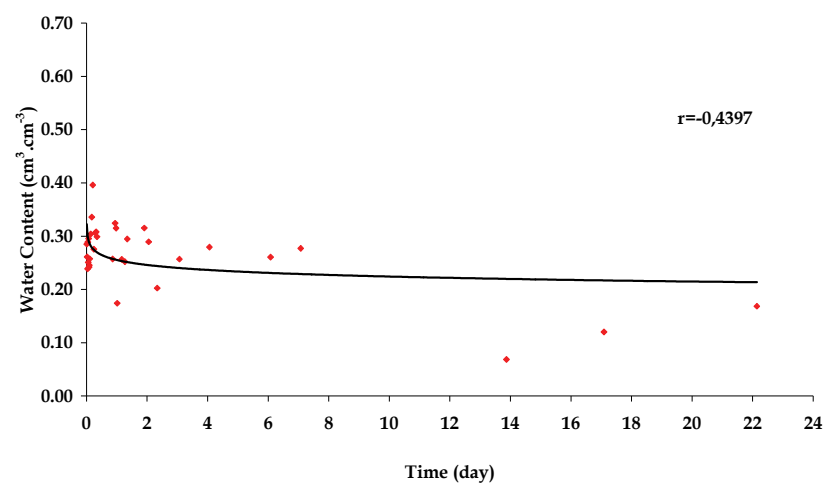

Fig. 7. Water redistribution $\mathrm{z}=8 \mathrm{~cm}$.

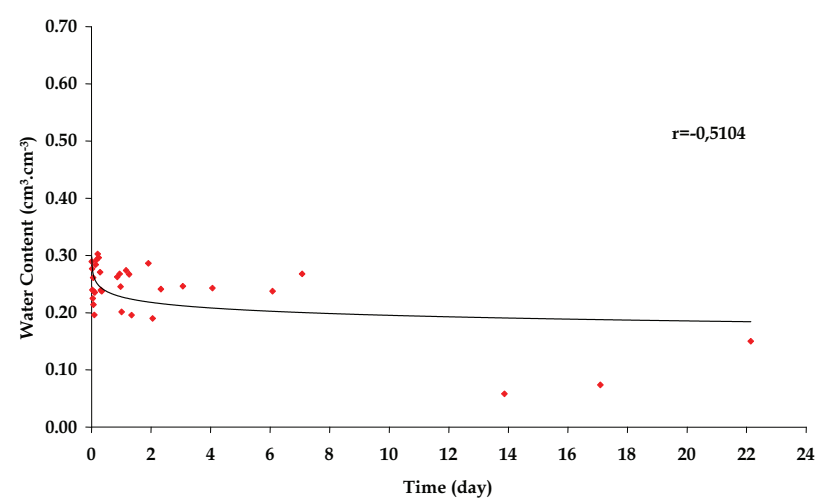

Fig. 8. Water redistribution $\mathrm{z}=12 \mathrm{~cm}$.

Figures 12 and 13 present the results of moisture content versus time for two depths (14 and $28 \mathrm{~cm}$ ) of another a soil column that was discarded. Increase of moisture content is verified in the course of time, quite different from the behavior presented in the previous figures. In this other column particularly, the soil was dried and cracks were created in the interface soil/paraffin, preferential pathways for water were found. The determination of the hydraulic conductivity of that soil column was not accomplished. 


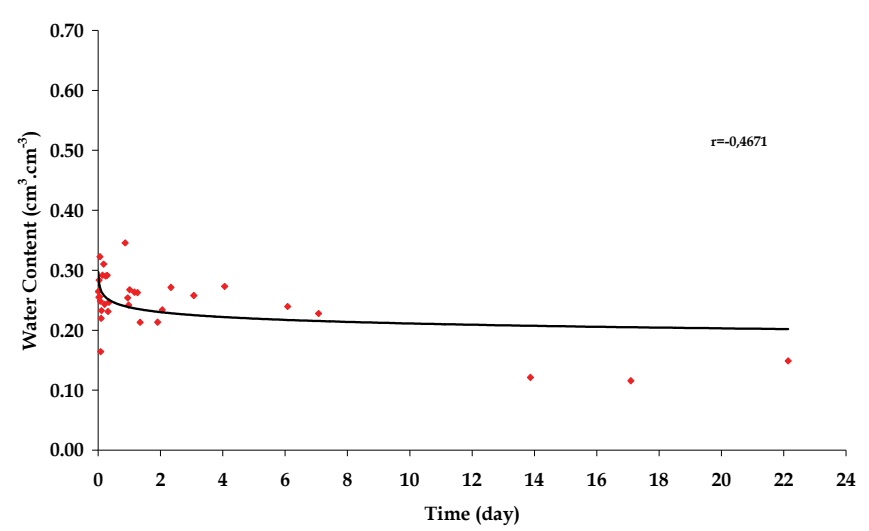

Fig. 9. Water redistribution $\mathrm{z}=16 \mathrm{~cm}$.

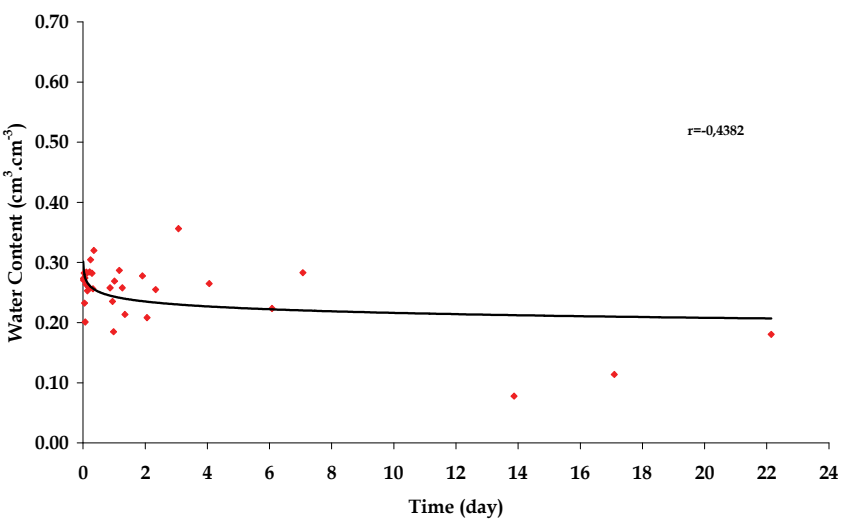

Fig. 10. Water redistribution $\mathrm{z}=18 \mathrm{~cm}$.

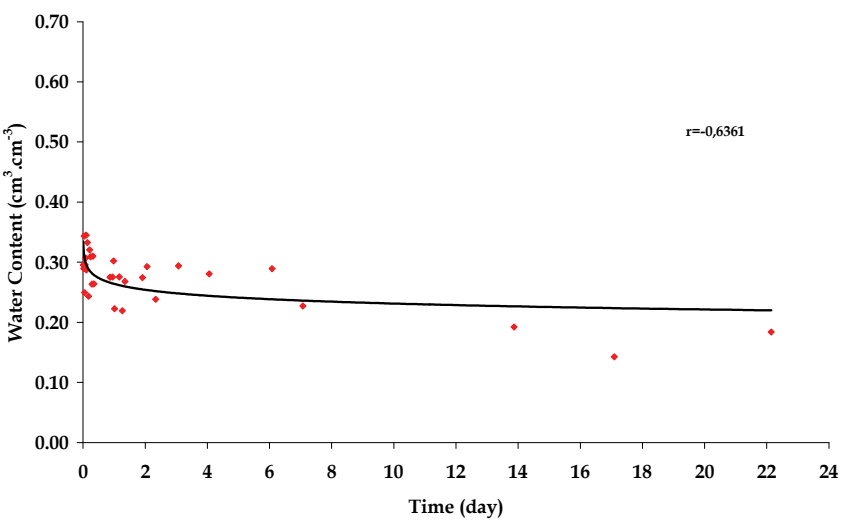

Fig. 11. Water redistribution $\mathrm{z}=20 \mathrm{~cm}$. 


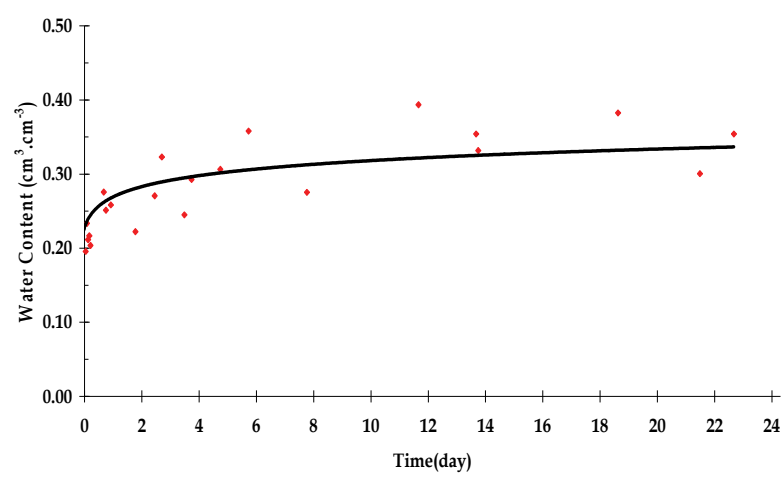

Fig. 12. Water redistribution $\mathrm{z}=14 \mathrm{~cm}$ from a discarded soil column.

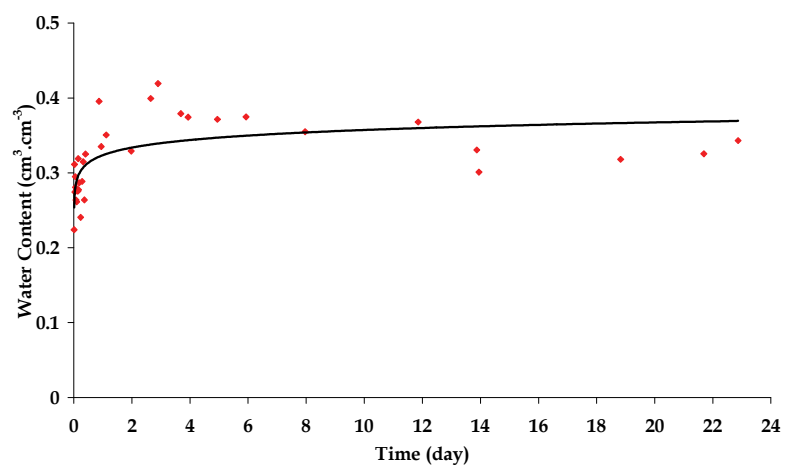

Fig. 13. Water redistribution $\mathrm{z}=14 \mathrm{~cm}$ from a discarded soil column.

\subsection{Empty column gammagraphy}

When the redistribution measurements finished the soil column was opened. The soil was removed from the column and only the shield (paraffin and gauzes) was preserved. The gammagraphy of empty column was performed following the procedures of section 3.3. The gammagraphy data were used to calculate the soil linear attenuation coefficient and also the soil moisture content (equations 18 and 25) in the process of water infiltration and redistribution.

\subsection{Hydraulic conductivity determination}

With the values of moisture content $[\theta(z, t)]$ in function of time for each depth level and also the data of redistribution, the values of hydraulic conductivity $[\mathrm{K}(\theta)]$ by the method of Sisson et al., 1980 was determined.

The experimental values of moisture content are normalized with the linear regression $\theta=\mathrm{a}$ $\ln \mathrm{t}+\mathrm{b}$ (according to equation 8 ), for a very short time $(t=0.0007$ day). The normalized values of moisture content (which will be used in the method of Sisson), called moisture model or theoretical values of moisture content redistribution are shown in Table 2. In the first line of the table the values of saturation moisture can be found. 
Using the data of moisture content redistribution with the model, the value of parameters $\gamma$, Ks was determined. With these parameters calculated for each depth level, it is possible to obtain the hydraulic conductivity function $\mathrm{K}(\theta)$. There is a small correlationship between moisture content with densities measured in each depth level. The depth level $\mathrm{z}=10 \mathrm{~cm}$, for example, has the lowest density value, as shown in Figure 6. indicating a high porous region compared to the other depths.

The curve fitting coefficient $r$ and the values $a$ and $b$ of the model $\theta=a \ln t+b$ to the experimental data are shown in Table 3.

The worst curve fittings to the experimental data were the depths $\mathrm{z}=10 \mathrm{~cm}$ and $14 \mathrm{~cm}$, where $r=-0.2875$ and -0.2721 respectively. In depths $z=2 \mathrm{~cm}$ and $20 \mathrm{~cm}$ the values of $r=-0.6730$ and 0.6361 , respectively, are the best results of the model application of the experimental data.

Table 4 presents the values of $\mathrm{K}_{\mathrm{s}}$ and $\gamma$, obtained by the method of Sisson with the equation (6), for all depth levels of the soil column ( $z=2 \mathrm{~cm}$ to $20 \mathrm{~cm}$ ). There's an increase of the conductivities $\mathrm{K}_{\mathrm{s}}$ in relationship to the depth. With these two parameters was possible to determine the hydraulic conductivity function $K(\theta)$ at each depth level, as can be seen in Table 5. Figure 14 shows the behavior of $\operatorname{lnK}\left[\mathrm{K}\left(\mathrm{cm} \cdot h^{-1}\right]\right.$ in function of $\theta\left(\mathrm{cm}^{3} \cdot \mathrm{cm}^{-3}\right)$ for the depth levels of $z=2$ to $z=20 \mathrm{~cm}$.

\begin{tabular}{|c|c|c|c|c|c|c|c|c|c|c|}
\hline \multirow{2}{*}{$\begin{array}{c}\text { Time } \\
\text { (day) }\end{array}$} & \multicolumn{10}{|c|}{$\mathrm{z}(\mathrm{cm})$} \\
\hline & 2 & 4 & 6 & 8 & 10 & 12 & 14 & 16 & 18 & 20 \\
\hline 0.0007 & 0.426 & 0.250 & 0.288 & 0.354 & 0.453 & 0.331 & 0.392 & 0.324 & 0.329 & 0.367 \\
\hline 0.2 & 0.290 & 0.185 & 0.196 & 0.277 & 0.400 & 0.251 & 0.315 & 0.257 & 0.262 & 0.287 \\
\hline 0.3 & 0.281 & 0.180 & 0.189 & 0.272 & 0.396 & 0.245 & 0.310 & 0.252 & 0.257 & 0.281 \\
\hline 0.4 & 0.274 & 0.177 & 0.185 & 0.268 & 0.394 & 0.241 & 0.306 & 0.249 & 0.254 & 0.277 \\
\hline 0.5 & 0.269 & 0.174 & 0.181 & 0.265 & 0.392 & 0.238 & 0.303 & 0.246 & 0.251 & 0.274 \\
\hline 0.7 & 0.261 & 0.170 & 0.176 & 0.260 & 0.388 & 0.233 & 0.299 & 0.243 & 0.247 & 0.269 \\
\hline 1.0 & 0.252 & 0.166 & 0.170 & 0.255 & 0.385 & 0.228 & 0.294 & 0.238 & 0.243 & 0.264 \\
\hline 1.5 & 0.242 & 0.161 & 0.163 & 0.250 & 0.381 & 0.222 & 0.288 & 0.234 & 0.239 & 0.258 \\
\hline 2.0 & 0.236 & 0.158 & 0.159 & 0.246 & 0.379 & 0.218 & 0.284 & 0.230 & 0.235 & 0.254 \\
\hline 2.5 & 0.230 & 0.156 & 0.155 & 0.243 & 0.377 & 0.215 & 0.281 & 0.228 & 0.233 & 0.251 \\
\hline 3.0 & 0.226 & 0.153 & 0.152 & 0.240 & 0.375 & 0.212 & 0.279 & 0.225 & 0.230 & 0.248 \\
\hline 3.5 & 0.222 & 0.152 & 0.150 & 0.238 & 0.373 & 0.210 & 0.277 & 0.224 & 0.229 & 0.246 \\
\hline 4.0 & 0.219 & 0.150 & 0.147 & 0.237 & 0.372 & 0.208 & 0.275 & 0.222 & 0.227 & 0.244 \\
\hline 4.5 & 0.216 & 0.149 & 0.146 & 0.235 & 0.371 & 0.207 & 0.273 & 0.221 & 0.226 & 0.243 \\
\hline 6.0 & 0.214 & 0.148 & 0.144 & 0.234 & 0.370 & 0.205 & 0.272 & 0.219 & 0.224 & 0.241 \\
\hline 7.0 & 0.209 & 0.145 & 0.141 & 0.231 & 0.368 & 0.203 & 0.270 & 0.217 & 0.222 & 0.239 \\
\hline 8.0 & 0.206 & 0.144 & 0.138 & 0.229 & 0.367 & 0.200 & 0.267 & 0.215 & 0.220 & 0.236 \\
\hline 8.5 & 0.201 & 0.141 & 0.135 & 0.226 & 0.365 & 0.198 & 0.265 & 0.213 & 0.218 & 0.234 \\
\hline 10.0 & 0.197 & 0.140 & 0.133 & 0.224 & 0.364 & 0.195 & 0.263 & 0.211 & 0.216 & 0.231 \\
\hline 11.5 & 0.194 & 0.138 & 0.130 & 0.222 & 0.362 & 0.193 & 0.261 & 0.210 & 0.215 & 0.229 \\
\hline 13.0 & 0.191 & 0.137 & 0.128 & 0.221 & 0.361 & 0.192 & 0.259 & 0.208 & 0.213 & 0.228 \\
\hline 15.0 & 0.187 & 0.135 & 0.126 & 0.219 & 0.360 & 0.190 & 0.257 & 0.207 & 0.211 & 0.225 \\
\hline 18.0 & 0.183 & 0.133 & 0.123 & 0.216 & 0.358 & 0.187 & 0.255 & 0.204 & 0.209 & 0.223 \\
\hline 20.0 & 0,181 & 0,132 & 0,121 & 0,215 & 0,357 & 0,186 & 0,253 & 0,203 & 0,208 & 0,221 \\
\hline
\end{tabular}

Table 2. Moisture content $\left(\mathrm{cm}^{3} \cdot \mathrm{cm}^{-3}\right)$ in each depth level. 


\begin{tabular}{|c|c|c|c|c|c|c|c|c|c|c|}
\hline \multirow{2}{*}{ terms } & \multicolumn{9}{|c|}{$\mathrm{z}(\mathrm{cm})$} \\
\cline { 2 - 11 } & 2 & 4 & 6 & 8 & 10 & 12 & 14 & 16 & 18 & 20 \\
\hline $\mathrm{a}$ & -0.024 & -0.012 & -0.016 & -0.014 & -0.009 & -0.014 & -0.013 & -0.012 & -0.012 & -0.014 \\
\hline $\mathrm{b}$ & 0.252 & 0.166 & 0.170 & 0.255 & 0.385 & 0.228 & 0.294 & 0.238 & 0.243 & 0.264 \\
\hline $\mathrm{r}$ & -0.673 & -0.415 & -0.484 & -0.440 & -0.287 & -0.510 & -0.272 & -0.467 & -0.438 & -0.636 \\
\hline
\end{tabular}

Table 3. Curve fitting correlation $\mathbf{r}$.

\begin{tabular}{|c|c|c|c|c|c|c|c|c|c|}
\hline \multicolumn{10}{|c|}{$\mathrm{z}(\mathrm{cm})$} \\
\hline 2 & 4 & 6 & 8 & 10 & 12 & 14 & 16 & 18 & 20 \\
\hline \multicolumn{8}{|c|}{ Hydraulic Conductivity (cm.h -1$)$} & $\mathrm{K}_{\mathrm{s}}$ \\
\hline 2.863 & 2.771 & 5.823 & 6.489 & 5.632 & 10.166 & 11.323 & 11.275 & 12.679 & 17.038 \\
\hline \multicolumn{8}{|c|}{$\gamma$ coefficient } \\
\hline 41.915 & 86.605 & 61.820 & 73.969 & 106.525 & 70.824 & 74.184 & 85.142 & 85.179 & 70.430 \\
\hline
\end{tabular}

Table $4 . \mathrm{K}_{\mathrm{s}}$ and $\gamma$ values.

Due to the exponential model for $\mathrm{K}(\theta)$, small variations for water moisture $\theta$ provide great differences between the values of hydraulic conductivity.

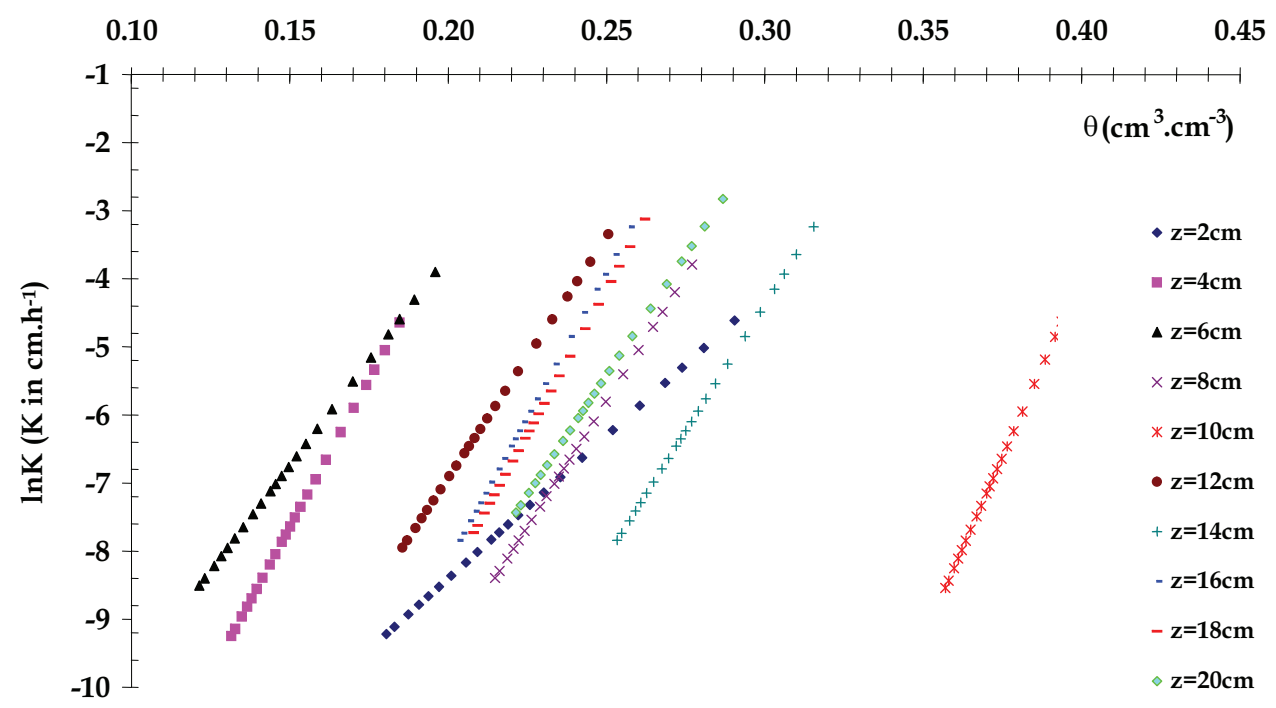

Fig. 14. In hydraulic conductivity versus moisture content. 


\begin{tabular}{|c|c|c|c|c|c|c|c|c|c|c|}
\hline \multirow{2}{*}{$\begin{array}{l}\text { Time } \\
\text { (day) }\end{array}$} & \multicolumn{10}{|c|}{$\mathrm{z}(\mathrm{cm})$} \\
\hline & 2 & 4 & 6 & 8 & 10 & 12 & 14 & 16 & 18 & 20 \\
\hline 0.2 & 0.00994 & 0.00962 & 0.02022 & 0.02253 & 0.01956 & 0.03530 & 0.03932 & 0.03915 & 0.04402 & 0.05916 \\
\hline 0.3 & 0.00663 & 0.00641 & 0.01348 & 0.01502 & 0.01304 & 0.02353 & 0.02621 & 0.02610 & 0.02935 & 0.03944 \\
\hline 0.4 & 0.00497 & 0.00481 & 0.01011 & 0.01127 & 0.00978 & \begin{tabular}{|l|}
0.01765 \\
\end{tabular} & 0.01966 & 0.01958 & 0.02201 & 0.02958 \\
\hline 0.5 & 0.00398 & 0.00385 & 0.00809 & 0.00901 & 0.00782 & 0.01412 & 0.01573 & 0.01566 & 0.01761 & 0.02366 \\
\hline 0.7 & 0.00284 & 0.00275 & 0.00578 & 0.00644 & 0.00559 & 0.01009 & 0.01123 & 0.01119 & 0.01258 & 0.01690 \\
\hline 1.0 & 0.00199 & 0.00192 & 0.00404 & 0.00451 & 0.00391 & 0.00706 & 0.00786 & 0.00783 & 0.00880 & 0.01183 \\
\hline 1.5 & 0.00133 & 0.00128 & 0.00270 & 0.00300 & 0.00261 & \begin{tabular}{|l|}
0.00471 \\
\end{tabular} & 0.00524 & 0.00522 & 0.00587 & 0.00789 \\
\hline 2.0 & 0.00099 & 0.00096 & 0.00202 & 0.00225 & 0.00196 & 0.00353 & 0.00393 & 0.00392 & 0.00440 & 0.00592 \\
\hline 2.5 & 0.00080 & 0.00077 & 0.00162 & 0.00180 & 0.00156 & 0.00282 & 0.00315 & 0.00313 & 0.00352 & 0.00473 \\
\hline 3.0 & 0.00066 & 0.00064 & 0.00135 & 0.00150 & 0.00130 & 0.00235 & 0.00262 & 0.00261 & 0.00293 & 0.00394 \\
\hline 3.5 & 0.00057 & 0.00055 & 0.00116 & 0.00129 & 0.00112 & 0.00202 & 0.00225 & 0.00224 & 0.00252 & 0.00338 \\
\hline 4.0 & 0.00050 & 0.00048 & 0.00101 & 0.00113 & 0.00098 & 0.00176 & 0.00197 & 0.00196 & 0.00220 & 0.00296 \\
\hline 4.5 & 0.00044 & 0.00043 & 0.00090 & 0.00100 & 0.00087 & 0.00157 & 0.00175 & 0.00174 & 0.00196 & 0.00263 \\
\hline 6.0 & 0.00040 & 0.00038 & 0.00081 & 0.00090 & 0.00078 & \begin{tabular}{|l|}
0.00141 \\
\end{tabular} & 0.00157 & 0.00157 & 0.00176 & 0.00237 \\
\hline 7.0 & 0.00033 & 0.00032 & 0.00067 & 0.00075 & 0.00065 & \begin{tabular}{|l|}
0.00118 \\
\end{tabular} & 0.00131 & 0.00131 & 0.00147 & 0.00197 \\
\hline 8.0 & 0.00028 & 0.00027 & 0.00058 & 0.00064 & 0.00056 & 0.00101 & 0.00112 & 0.00112 & 0.00126 & 0.00169 \\
\hline 8.5 & 0.00023 & 0.00023 & 0.00048 & 0.00053 & 0.00046 & 0.00083 & 0.00093 & 0.00092 & 0.00104 & 0.00139 \\
\hline 10.0 & 0.00020 & 0.00019 & 0.00040 & 0.00045 & 0.00039 & 0.00071 & 0.00079 & 0.00078 & 0.00088 & 0.00118 \\
\hline 11.5 & 0.00017 & 0.00017 & 0.00035 & 0.00039 & 0.00034 & 0.00061 & 0.00068 & 0.00068 & 0.00077 & 0.00103 \\
\hline 13.0 & 0.00015 & 0.00015 & 0.00031 & 0.00035 & 0.00030 & 0.00054 & 0.00060 & 0.00060 & 0.00068 & 0.00091 \\
\hline 15.0 & 0.00013 & 0.00013 & \begin{tabular}{|l|}
0.00027 \\
\end{tabular} & 0.00030 & \begin{tabular}{|l|}
0.00026 \\
\end{tabular} & \begin{tabular}{|l|}
0.00047 \\
\end{tabular} & \begin{tabular}{|l|}
0.00052 \\
\end{tabular} & \begin{tabular}{|l|}
0.00052 \\
\end{tabular} & \begin{tabular}{|l|}
0.00059 \\
\end{tabular} & 0.00079 \\
\hline 18.0 & 0.00011 & 0.00011 & 0.00022 & 0.00025 & 0.00022 & 0.00039 & 0.00044 & 0.00044 & 0.00049 & 0.00066 \\
\hline 20.0 & 0.00010 & 0.00010 & 0.00020 & 0.00023 & 0.00020 & 0.00035 & 0.00039 & 0.00039 & 0.00044 & 0.00059 \\
\hline
\end{tabular}

Table 5. Hydraulic conductivity K $(\theta)\left(\mathrm{cm} \cdot \mathrm{h}^{-1}\right)$ values.

\section{Conclusion}

With the methodology employed was possible to analyze the temporal and spatial evolution of moisture content $\theta(z, t)$ in the undisturbed soil column. The results of hydraulic conductivity using the method of Sisson indicate a decrease of $K(\theta)$ in relation to the depth. With the gamma ray transmission technique was also possible to detect a variation on the soil compaction inside the column, by the densitometry data.

The combination of the two methods applied in this study, Sisson and Gamma Ray Transmission, was effective to determine the hydraulic conductivity of undisturbed soil column. However, the combination can be used for application in infiltration of water in other porous media to evaluate the temporal evolution of the water flow.

Another important tool of the GRT, a non-destructive technique, is to analyze the porous structural variability of samples along its length. The gammagraphy, specially the densitometry presented in section 3.3, with some approximations, can also be applied to study internal structures of a large range of samples. 


\section{References}

Al-Houri, Z.M.; Barber, M.E.; Yonge, D.R.; Ullman, J.L.; Beutel, M.W. (2009). Impacts of frozen soils on the performance of infiltration treatment facilities. Cold Regions Science and Technology, Vol. 59, 51-57

Appoloni, C.R. \& Rios, E.A. (1994), Mass attenuation coefficients of brazilian soils in the range 10-1450 keV. Applied Radiation Isotopes, Vol. 45, 287-291

Buckingham, E. (1907) Studies on the movement of soil moisture. Bureau Soils Bulletin, 38, Washington DC, USA

Chong, S.K.; Green, R.E.; Ahuja, L.R. (1981). Simple in situ determination of hydraulic conductivity by power function descriptions of drainage. Water Resources Research, Vol. 17, 1109-1114

Coppola, A.; Santinib, A.; Botti, P.; Vacca, S.; Comegna, V.; Severino, G. (2004) Methodological approach for evaluating the response of soil hydrological behavior to irrigation with treated municipal wastewater. Journal of Hydrology, Vol. 292, 114-134

Darcy, H. (1856). Les fontaines publique de la ville de Dijon, Dalmont, Paris

Ferraz, E.S.B. (1974). Determinação simultânea de densidade e umidade de solos por atenuação de raios gama do 137Cs e 241Am. PhD. Thesis, ESALQ/USP, Piracicaba, Brazil

Gerward, N.; Guilbert, K.B.; Jensen and H. Levring. (2001), X ray absorption in matter. Reengineering XCOM. Radiation Physics and Chemistry, Vol. 60, 23-24

Hillel, D.; Krentos, V.D.; Stylianou, Y. (1972). Procedure and test of an internal drainage method for measuring soil hydraulic characteristics in situ. Soil Science. Vol. 114, 395-400

Jones, A.J. \& Wagenet, R.J. (1984). In situ estimation of hydraulic conductivity using simplified methods. Water Resource Research, Vol. 20, 1620-1626

Klute, A. (1972). The determination of the hydraulic conductivity and diffusivity of unsaturated soils. Soil Science, Vol. 113, 264-276

Lax, P.D. The formation and decay of shock waves. (1972). American Mathematical Monthly, Vol. 79, 227-241, apud Sisson, J.B.; Ferguson, A.H.; Van Genuchten, M.TH. (1980). Simple method for predicting drainage from field plots. Soil Science Society American Journal, Vol. 44, 1147-1152

Libardi, P. L.; Reichardt, K.; Nielsen, D. R.; Biggar, J. W. (1980).Simple field methods for estimating soil hydraulic conductivity. Soil Science Society American Journal, V.44, 3-7.

Ma, Y.; Feng, S.; Su, D.; Gao, G.; Huo, Z. (2010). Modeling water infiltration in a large layered soil column with a modified Green-Ampt model and HYDRUS-1D, Computers and Electronics in Agriculture, 71S S40 - S47

Moreira, A.C., Appoloni, C.R. (2006). Mass attenuation coefficient of the Earth, Moon and Mars samples over $1 \mathrm{keV}-100 \mathrm{GeV}$ energy range. Applied Radiation and Isotopes. Vol. 64, 1065-1073

Oliveira, J.C.M. (1991). Determinação de parâmetros do solo durante a infiltração horizontal e redistribuição da água por atenuação de raios gama e tensiometria. $\mathrm{PhD}$ Thesis CENAQ/USP, Piracicaba, Brazil,

Portezan Filho, O. (1997). Análise crítica da determinação da condutividade hidráulica do solo utilizando atenuação de radiação gama monoenergética. PhD Thesis, IPEN/USP, São Paulo, Brazil

Reichardt, K. (1965) Uso da radiação gama na determinação da umidade e densidade do solo. PhD Thesis, Escola Superior de Agricultura Luis de Queiros. Piracicaba, Brazil

Reginato, R.J. \& Van Bavel, C.H.M. (1964) Soil water measurement with gamma attenuation. Soil Science Society American Journal, Vol. 28, 721-724 
Richards, L.A. (1931). Capillary conduction of liquid through porous media. Physics, Vol. 1, 318-333

Siegbahn, K. Alpha-, Beta- and Gamma-Ray Spectroscopy. (1965) North-Holland Publishing Company, Amsterdam, New York, Oxford, 37-76

Sisson, J.B.; Ferguson, A.H.; Van Genuchten, M.TH. (1980). Simple method for predicting drainage from field plots. Soil Science Society American Journal, Vol. 44, 1147-1152 


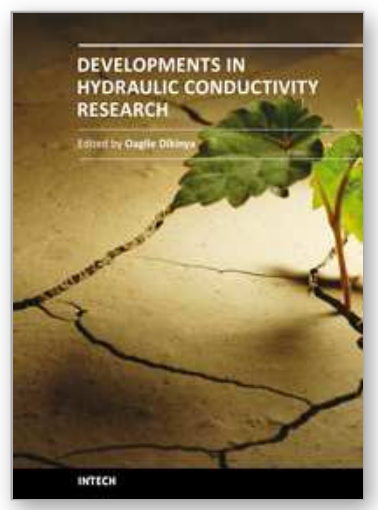

\author{
Developments in Hydraulic Conductivity Research \\ Edited by Dr. Oagile Dikinya
}

ISBN 978-953-307-470-2

Hard cover, 270 pages

Publisher InTech

Published online 28, February, 2011

Published in print edition February, 2011

This book provides the state of the art of the investigation and the in-depth analysis of hydraulic conductivity from the theoretical to semi-empirical models perspective as well as policy development associated with management of land resources emanating from drainage-problem soils. A group of international experts contributed to the development of this book. It is envisaged that this thought provoking book will excite and appeal to academics, engineers, researchers and University students who seek to explore the breadth and indepth knowledge about hydraulic conductivity. Investigation into hydraulic conductivity is important to the understanding of the movement of solutes and water in the terrestrial environment. Transport of these fluids has various implications on the ecology and quality of environment and subsequently sustenance of livelihoods of the increasing world population. In particular, water flow in the vadose zone is of fundamental importance to geoscientists, soil scientists, hydrogeologists and hydrologists and allied professionals.

\title{
How to reference
}

In order to correctly reference this scholarly work, feel free to copy and paste the following:

Anderson Camargo Moreira, Otávio Portezan Filho, Fábio Henrique de Moraes Cavalcante and Carlos Roberto Appoloni (2011). Determination of Hydraulic Conductivity of Undisturbed Soil Column: a Measurement Accomplished with the Gamma Ray Transmission Technique, Developments in Hydraulic Conductivity Research, Dr. Oagile Dikinya (Ed.), ISBN: 978-953-307-470-2, InTech, Available from: http://www.intechopen.com/books/developments-in-hydraulic-conductivity-research/determination-of-hydraulicconductivity-of-undisturbed-soil-column-a-measurement-accomplished-with- $t$

\section{INTECH}

open science | open minds

\section{InTech Europe}

University Campus STeP Ri

Slavka Krautzeka 83/A

51000 Rijeka, Croatia

Phone: +385 (51) 770447

Fax: +385 (51) 686166

www.intechopen.com

\section{InTech China}

Unit 405, Office Block, Hotel Equatorial Shanghai

No.65, Yan An Road (West), Shanghai, 200040, China 中国上海市延安西路65号上海国际贵都大饭店办公楼405单元

Phone: +86-21-62489820

Fax: +86-21-62489821 
(C) 2011 The Author(s). Licensee IntechOpen. This chapter is distributed under the terms of the Creative Commons Attribution-NonCommercialShareAlike-3.0 License, which permits use, distribution and reproduction for non-commercial purposes, provided the original is properly cited and derivative works building on this content are distributed under the same license. 